\title{
Thrombin induces collagen gel contraction partially through PAR1 activation and PKC-E
}

\author{
Q. Fang*, X. Liu*, S. Abe*, T. Kobayashi*, X.Q. Wang*, T. Kohyama*, M. Hashimoto*, T. Wyatt*, \\ S.I. Rennard*
}

Thrombin induces collagen gel contraction partially through PARl activation and

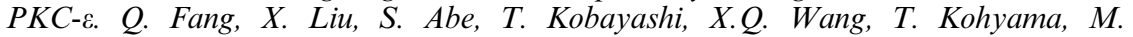
Hashimoto, T. Wyatt, S.I. Rennard. (C) ERS Journals Ltd 2004.

ABSTRACT: The ability of fibroblasts to contract three-dimensional collagen gels has been used as an in vitro model of the tissue contraction which characterises both normal repair and fibrosis. Among its actions, thrombin can activate the protease-activated receptor (PAR)1 and, thereby, stimulate inflammation and repair. The current study evaluated whether thrombin could stimulate fibroblast-mediated collagen gel contraction by activating PAR1 and whether its downstream signalling depends on protein kinase C (PKC)- $\varepsilon$.

Human foetal lung fibroblasts (HFL-1) were cultured in three-dimensional collagen gels and the area of the gels was measured by image analyser.

Both thrombin and TFLLR, a selective PAR1 agonist, stimulated collagen gel contraction mediated by HFL-1. After RNA interference-mediated PAR1 knockdown in HFL-1, both thrombin and the PAR1 agonist-induced gel contraction were partially inhibited (by $22.4 \pm 2.2 \%$ and $17.6 \pm 5.6 \%$, respectively). The gel contraction stimulated by thrombin was also reduced by a nonspecific PKC inhibitor and a calciumindependent PKC- $\varepsilon$ inhibitor. Both thrombin and TFLLR significantly increased PKC$\varepsilon$ activity, and this effect was blocked by PAR1 knockdown.

Thrombin stimulates collagen gel contraction at least partially through activation of protease-activated receptor 1 and protein kinase $C-\varepsilon$, and may contribute to tissue remodelling in inflammatory airway and lung diseases.

Eur Respir J 2004; 24: 918-924.
*University of Nebraska Medical Center, Omaha, NE, USA and ${ }^{\#}$ University of Tokyo, Tokyo, Japan.

Correspondence: S.I. Rennard

University of Nebraska Medical Center

985125 Nebraska Medical Center

Omaha

NE

USA

Fax: 14025594878

E-mail: srennard@unmc.edu

Keywords: Gel contraction protease-activated receptor protein kinase $\mathrm{C}-\varepsilon$

short interfering RNA

thrombin

Received: January 152004

Accepted after revision: August 222004

This work was funded by the Larson Endowment, University of Nebraska Medical Center and NIH grant RO1-HL64088.
Alterations in tissue structure are characteristic features of many chronic lung diseases. In interstitial lung diseases, fibroblasts accumulate together with the collagenous extracellular matrix they produce. Importantly, this fibrotic alteration is associated with disruption of normal tissue architecture. Characteristically, fibrotic tissues contract, distorting normal anatomy and altering function [1]. Similar tissue remodelling is now recognised to occur in airways disease as well, where it may be a major contributor to airway narrowing and fixed airflow limitation [2,3]. Identification of the mechanisms which lead to these tissue alterations is a major goal in developing strategies to alter the natural history of many chronic lung disorders.

While the mechanisms that lead to tissue remodelling are incompletely understood, fibroblasts are believed to play a pivotal role. In this regard, the ability of fibroblasts to contract three-dimensional collagen gels has been used as an in vitro model of the tissue contraction which characterises fibrosis [4]. Many mediators, including platelet-derived growth factor, transforming growth factor (TGF), prostaglandin $\mathrm{D}_{2}$, lysophosphatidic acid and bradykinin, can stimulate fibroblast-mediated collagen gel contraction, and have been suggested to have a pro-fibrotic role [5-9]. While the signal transduction pathways directly responsible for stimulating collagen gel contraction remain to be defined completely, several stimulators of gel contraction appear to act through protein kinase $\mathrm{C}(\mathrm{PKC})-\varepsilon$ [7]. This novel, calciumindependent member of the PKC family is known to regulate cytoskeletal reorganisation and to modulate cell spreading and adhesion [10]. Conversely, many mediators, including interleukin-1, tumour necrosis factor- $\alpha$, prostaglandin $\mathrm{E}_{2}$ and nitric oxide, can inhibit fibroblast-mediated collagen gel contraction and may have an anti-fibrotic function [11, 12]. The balance among these various mediators may be crucial in determining whether tissue injury is followed by inadequate, excessive or effective tissue repair.

Thrombin is one of the mediators probably present in the inflammatory milieu in the airway. Thrombin is a serine protease activated from pro-thrombin as part of the clotting cascade. In addition to cleaving fibrinogen and serving as the final effector for blood clotting, thrombin has other actions on many cell types. In particular, it can stimulate a number of functions in fibroblasts and other cells consistent with a prorepair function [13]. Thrombin, moreover, has been reported to be elevated in several chronic inflammatory diseases, including lung diseases characterised by fibrotic tissue remodelling, such as scleroderma and asthma [14, 15].

Thrombin is capable of activating cells by a number of mechanisms. Through its proteolytic action, thrombin can generate secondary mediators. Thrombin can also cleave protease-activated receptors (PARs) on the cell surface. The PARs are G-protein-coupled receptors that are also 
substrates for proteolytic cleavage. Upon cleavage, a novel site on the receptor is exposed that can result in autoactivation of the receptor. To date, four types of PARs have been identified and thrombin activates at least three members of the PAR family, including PAR1, PAR3 and PAR4. Much evidence accumulated to date has highlighted the importance of PAR1 as an activator of a number of cell types [16, 17].

The current study was, therefore, designed to determine whether thrombin could stimulate fibroblast-mediated collagen gel contraction by activating the PAR1 receptor. Furthermore, the role of PKC- $\varepsilon$ as a downstream mediator of thrombin acting through PAR1 to direct contraction was assessed.

\section{Materials and methods}

\section{Materials}

Type I collagen was extracted from rat tail tendons (RTTC) as previously described $[18,19]$. Briefly, tendons were excised from rat tails, and the tendon sheath and other connective tissues were removed carefully. Repeated washing with Trisbuffered saline $(0.9 \% \mathrm{NaCl}, 10 \mathrm{mM}$ Tris, $\mathrm{pH} 7.5)$ was followed by dehydration and sterilisation with 50, 75, 95 and $100 \%$ ethanol. Type I collagen was extracted in $6 \mathrm{mM}$ hydrochloric acid at $4{ }^{\circ} \mathrm{C}$ for $24 \mathrm{~h}$. The supernatant was harvested by centrifugation at $2,000 \times \mathrm{g}$ for $2 \mathrm{~h}$ at $4{ }^{\circ} \mathrm{C}$. Protein concentration was determined by weighing a lyophilised aliquot from each lot of collagen solution. Sodium dodecyl sulfate polyacrylamide gel electrophoresis (SDS-PAGE) routinely demonstrated no detectable proteins other than type I collagen. The RTTC was stored at $4{ }^{\circ} \mathrm{C}$ until use.

Thrombin from human plasma and EGTA were purchased from Sigma (St. Louis, MO, USA). The human PAR1 agonists, TFLLR and TFLLR-NH $\mathrm{N}_{2}$, PAR1 agonist negative control, RLLFT- $\mathrm{NH}_{2}$, and the human PAR4 agonist, GYPGQV, were synthesised by Genemed Synthesis Inc. (South San Francisco, CA, USA). Calphostin C, BAPTA/ AM, Ro-31-8220, Gö6976 and TMB-8 were obtained from Calbiochem (San Diego, CA, USA). TGF- $\beta 1$ was purchased from R\&D Systems, Inc. (Minneapolis, MN, USA). Tissue culture supplements, FBS and media were purchased from GIBCO (Life Technologies, Grand Island, NY, USA).

\section{Cell culture}

Human foetal lung fibroblasts (HFL-1) were obtained from the American Type Culture Collection (Rockville, MD, USA). The cells were cultured in $100-\mathrm{mm}^{2}$ tissue culture dishes (FALCON; Becton-Dickinson Labware, Franklin Lakes, NJ, USA) in Dulbecco's modified Eagle's medium (DMEM) supplemented with $10 \% \mathrm{FCS}, 50 \mathrm{U} \cdot \mathrm{mL}^{-1}$ penicillin, $50 \mu \mathrm{g} \cdot \mathrm{mL}^{-1}$ streptomycin and $1 \mu \mathrm{g} \cdot \mathrm{mL}^{-1}$ fungizone. The fibroblasts were passaged every 3-5 days. Subconfluent fibroblasts were trypsinised (trypsin-EDTA; $0.05 \%$ trypsin, $0.53 \mathrm{mM}$ EDTA-4Na) and used for collagen gel culture. Fibroblasts used in these experiments were between cell passage 14 and 19 .

\section{Collagen gel preparation and contraction assay}

Collagen gels were prepared as described previously [19]. Briefly, the appropriate amount of RTTC was mixed with distilled water, $4 \times$ concentrated DMEM and the cell suspension, so that the final mixture resulted in $0.75 \mathrm{mg} \cdot \mathrm{mL}^{-1}$ of collagen, $3.0 \times 10^{5}$ cells $\cdot \mathrm{mL}^{-1}$ and a physiological ionic strength. Fibroblasts were routinely added last to minimise damage during the preparation of collagen gels. One half millilitre of the mixture was cast into each well of 24-well tissue culture plates (FALCON; Becton Dickinson Labware). Gelation occurred in $\sim 20 \mathrm{~min}$ at room temperature, after which the gels were released and transferred to $60-\mathrm{mm}^{2}$ tissue culture dishes, containing $5 \mathrm{~mL}$ of serum-free DMEM with or without thrombin or the PAR agonists in the presence or absence of inhibitors. The floating gels were then incubated at $37^{\circ} \mathrm{C}$ in a $5 \% \mathrm{CO}_{2}$ atmosphere for various periods of time. The areas of floating gels were measured using an image analyser (Optomax, Burlington, MA, USA). Gel contraction was measured in triplicate gels within each experiment and no less than three separate experiments were performed for each unique parameter.

\section{Preparation and transfection of siRNA targeting PARI}

Short interfering RNA (siRNA) targeting human PAR1 was designed according to the methods as described by ElbASHIR et al. [20]. The siRNA sequence targeting PAR1 was from position 288-308, relative to the first nucleotide of the start codon (GeneBank accession number BC002464). Twenty-one-nt RNAs were chemically synthesised by Dharmacon (Lafayette, CO, USA). The sequences of each siRNA pair were as follows: 5'-CAA AUG CCA CCU UAG AUC CdTdT-3' and 5'-GGA UCU AAG GUG GCA UUU GdTdT-3'. Annealing of siRNAs was performed as described by the manufacturer. Briefly, equal content of each siRNA oligo was incubated in annealing buffer (100 mM KOAc, $30 \mathrm{mM}$ HEPES-KOH, pH 7.4, $2 \mathrm{mM} \mathrm{MgOAc)}$ for $1 \mathrm{~min}$ at $90^{\circ} \mathrm{C}$, followed by $1 \mathrm{~h}$ at $37^{\circ} \mathrm{C}$. The final concentration of the siRNA duplex was $20 \mu \mathrm{M}$ in $1 \times$ annealing buffer. In addition, commercially available PAR1 siRNA SMARTpool and siRNA SMARTpool negative control were purchased from Dharmacon. Transfection with TransIT-TKO (Mirus Corporation, Madison, WI, USA) was performed as described previously [20]. Twenty-four hours after transfection, the efficacy of knockdown was assessed by Western blot. Cell viability was evaluated by calcein AM and ethidium homodimev-1, a two-colour fluorescence-based method, using the LIVE/DEAD Kit, following the manufacturer's instructions (Molecular Probe, Eugene, OR, USA).

\section{Western blotting}

Cells were washed with PBS twice and lysed with lysing buffer containing $35 \mathrm{mM}$ Tris- $\mathrm{HCl}$, pH 7.4, 0.4 mM EGTA, $10 \mathrm{mM} \mathrm{MgCl} 2,0.1 \%$ Triton X-100 and protease inhibitors (3 $\mu \mathrm{g} \cdot \mathrm{mL}^{-1}$ aprotinin, $1 \mu \mathrm{M}$ phenylmethanesulphonylfluoride and $10 \mu \mathrm{g} \cdot \mathrm{mL}^{-1}$ leupeptin). The cells were then gently scraped and the lysate was transferred to a microcentrifuge tube. After sonication, the samples were centrifuged at $10,000 \times \mathrm{g}$ for $10 \mathrm{~min}$ at $4{ }^{\circ} \mathrm{C}$. The protein content of the supernatants was measured and $10 \mu \mathrm{g}$ of each sample was analysed by SDSPAGE in $10 \%$ polyacrylamide gels. After separation by electrophoresis, the proteins were transferred to polyvinyl difluoride membranes (Bio-Rad Laboratories, Hercules, CA, USA). Membranes were blocked in 5\% nonfat milk in PBSTween at room temperature for $1 \mathrm{~h}$ and then probed with anti-PAR1, as well as anti-PAR2, anti-PAR3 and anti-PAR4 antibodies (Santa Cruz Biotechnology, Inc., Santa Cruz, CA, USA). Target proteins were subsequently detected using horseradish peroxidase-conjugated second antibody in conjunction with enhanced chemiluminescence detection system 
(ECL; Amersham Biosciences UK Ltd, Little Chalfont, UK). The anti-PAR 1 and its second antibody were then stripped from the membranes using stripping buffer (100 mM 2mercaptoethanol, $2 \% \mathrm{SDS}, 62.5 \mathrm{mM}$ Tris- $\mathrm{Cl}, \mathrm{pH} 6.7)$ at $50^{\circ} \mathrm{C}$ for $30 \mathrm{~min}$. Vimentin expression was detected using antivimentin mAb (DAKO Corporation, Carpinteria, CA, USA).

\section{$P K C-\varepsilon$ activity assay}

PKC- $\varepsilon$ activity was determined in crude whole-cell fractions. The assay employed was a modification of procedures previously described [21], using $900 \mu \mathrm{M}$ PKC- $\varepsilon$-specific substrate peptide (Calbiochem), $8 \mu \mathrm{M}$ phosphatidyl-L-serine, $24 \mu \mathrm{g} \cdot \mathrm{mL}^{-1}$ PMA, $30 \mathrm{mM}$ dithiothreitol, $150 \mu \mathrm{M}$ ATP, $45 \mathrm{mM} \mathrm{Mg}\left(\mathrm{C}_{2} \mathrm{H}_{3} \mathrm{O}_{2}\right)_{2}$ and $10 \mu \mathrm{Ci} \cdot \mathrm{mL}^{-1}\left[\gamma_{-}{ }^{32} \mathrm{P}\right]$ ATP in a Tris- $\mathrm{HCl}$ buffer $(\mathrm{pH} 7.5)$. Samples $(20 \mu \mathrm{L})$ were added to $40 \mu \mathrm{L}$ of the above reaction mixture and incubated for $15 \mathrm{~min}$ at $30^{\circ} \mathrm{C}$. Incubations were halted by spotting $50 \mu \mathrm{L}$ of each sample onto P-81 phosphocellulose papers (Whatman). Papers were then washed five times for $5 \mathrm{~min}$ each in phosphoric acid (75 mM), washed once in ethanol, dried and counted in nonaqueous scintillant, as previously described [22]. Kinase activity was expressed in relation to total cellular protein assayed and calculated in $\mathrm{pmol} \cdot \mathrm{min}^{-1} \cdot \mathrm{mg}^{-1}$. All samples were assayed in triplicate and each experiment was repeated on no less than three separate occasions.

\section{Statistical analysis}

Individual experiments included triplicate gels within an experiment or for all experimental conditions. Results were always confirmed by repeating each experiment on separate occasions at least three times. Statistical comparisons were made from all experiments, including both the within- and between-group variance. PKC- $\varepsilon$ was expressed as fold change in activation compared to control, untreated cells for all experiments. Group data were analysed by one-way ANOVA. Differences between series of data that appeared statistically different were corrected by Tukey's test. A $p<0.05$ was considered significant.

\section{Results}

\section{Effect of thrombin on collagen gel contraction}

Under control conditions, HFL-1 contracted the collagen gels progressively over the 5-day culture period. Collagen gel contraction was augmented by thrombin over the entire 5days incubation period (fig. 1). At day 1, the size of gels treated with thrombin $(2,10$ and $50 \mathrm{nM})$ was $42.9 \pm 2.1$, $35.1 \pm 1.6$ and $32.3 \pm 1.5 \%$ of initial gel size, respectively $(\mathrm{p}<0.01$, compared with control gels $78.0 \pm 2.8 \%)$. After 5 days of culture, the size of gels treated with thrombin $(2,10$ and $50 \mathrm{nM}$ ) was $29.3 \pm 3.9,8.6 \pm 0.4,5.9 \pm 0.4 \%$ of original size, respectively $(\mathrm{p}<0.01$, compared with control gels $46.4 \pm 2.8 \%)$.

\section{Effect of the proteolytic activity on thrombin-induced collagen gel contraction}

To examine whether proteolytic activity of thrombin was required for thrombin-induced collagen gel contraction, hirudin, a thrombin inhibitor, was used. Hirudin itself had no effect on collagen gel contraction. In contrast, the

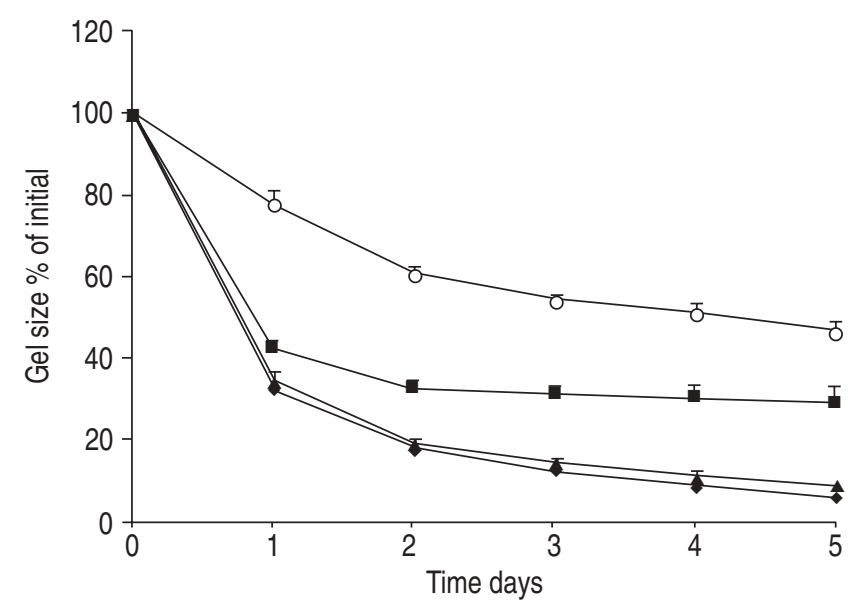

Fig. 1.-Effect of thrombin (2 nM: $\boldsymbol{\square} ; 10 \mathrm{nM}: \boldsymbol{\Delta}$; $50 \mathrm{nM}$ : $\boldsymbol{\nabla})$ on collagen gel contraction mediated by human foetal lung fibroblasts compared to control $(\bigcirc)$. Data are presented as mean \pm SEM for three separate experiments, each of which included triplicate gels for each condition.

stimulatory effect of thrombin on collagen gel contraction was completely blocked by hirudin (fig. 2).

\section{Role of PAR1 in thrombin-induced collagen gel contraction}

Two separate approaches were used to evaluate the role of PAR1 in mediating thrombin-induced collagen gel contraction. First, a PAR1-selective agonist was utilised to mimic the effects of thrombin. Secondly, the technique of RNA interference (RNAi) was used to decrease PAR1 expression on cultured fibroblasts.

To determine whether PAR1 activation was involved in thrombin-induced collagen gel contraction, the effect of the selective PAR1 agonist, TFLLR, was measured. TFLLR, at a concentration of $600 \mu \mathrm{M}$, significantly augmented collagen gel contraction over the 5 -day culture period (fig. $3 \mathrm{a}, \mathrm{p}<0.01$ ). TFLLR augmented fibroblast-mediated collagen gel contraction at all time points observed. At day 1, gel size was $58.5 \pm 1.7 \%$ of initial gel size in the presence of TFLLR versus $81.6 \pm 1.2 \%$ for control gels $(\mathrm{p}<0.01)$. After 5 days, this

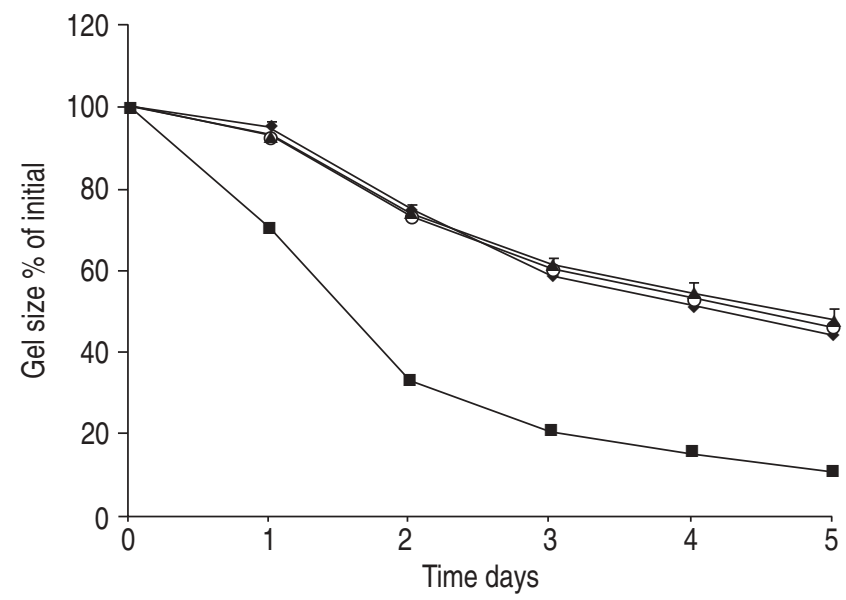

Fig. 2.-Effect of hirudin ( ) on thrombin-induced collagen gel contraction ( $\boldsymbol{\square}$ ) mediated by human foetal lung fibroblasts compared to control $(\bigcirc)$. The effect of hirudin alone $(\boldsymbol{\Delta})$ is also shown. Data are presented as mean \pm SEM for three separate experiments, each of which included triplicate gels for each condition. 

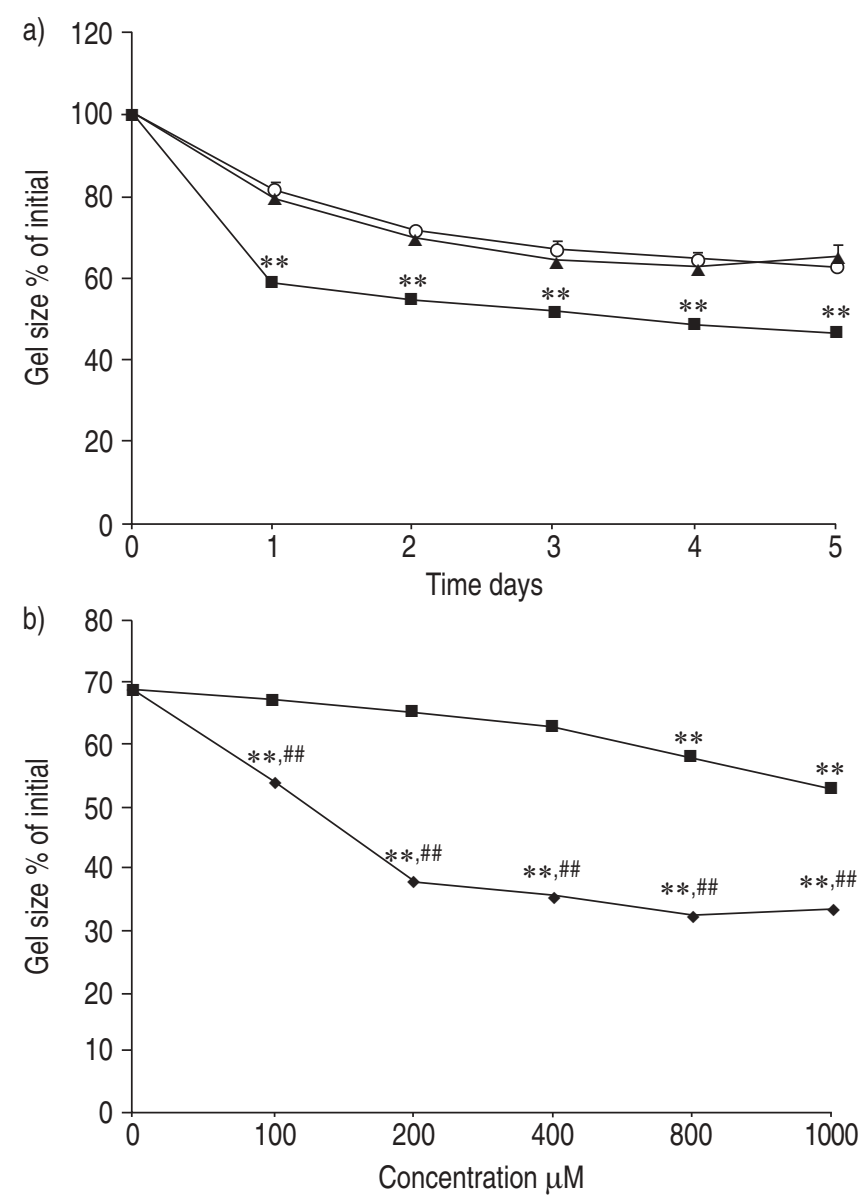

Fig. 3. - Effect of protease-activated receptor (PAR)1 agonist on collagen gel contraction mediated by human foetal lung fibroblasts. a) Effect of PAR1 agonist (TFLLR; - ) and PAR4 agonist (GYPGQV; $\mathbf{\Delta}$ ) compared with control $(\bigcirc)$. **: p<0.01. b) Effect of PAR1 agonist (TFLLR-NH $\mathrm{NH}_{2}$; ) and its negative control peptide (RLLFT-NH ${ }_{2}$; 口). ${ }^{* *}: \mathrm{p}<0.01$ as compared with control; ${ }^{\# \#: ~} \mathrm{p}<0.01$ as compared with RLLFT- $\mathrm{NH}_{2}$. Data are presented as mean \pm SEM for three separate experiments, each of which included triplicate gels for each condition.

difference was maintained $(46.5 \pm 2.0$ versus $62.3 \pm 2.7 \%$, $\mathrm{p}<0.01)$. No effect on gel contraction was observed with the PAR4 agonist GYPGQV at $600 \mu \mathrm{M}$. Amide modification of the PAR1 agonist (TFLLR-NH $\mathrm{N}_{2}$ ), which is known to increase potency, and its scrambled negative control (RLLFT-NH $\left.{ }_{2}\right)$ were also tested (fig. 3b). TFLLR-NH $\mathrm{NH}_{2}(100-1,000 \mu \mathrm{M})$ significantly stimulated gel contraction $(\mathrm{p}<0.01)$. No effect on gel contraction was observed with RLLFT-NH $\mathrm{N}_{2}$ at lower concentrations. RLLFT- $\mathrm{NH}_{2}$ at 800 and $1,000 \mu \mathrm{M}$ also stimulated gel contraction, although the potency was far less than TFLLR-NH $2(\mathrm{p}<0.01)$.

The second approach to confirm the role of PAR1 in mediating thrombin-stimulated fibroblast contraction of threedimensional collagen gels was to use RNAi to specifically suppress PAR1 expression in cultured HFL-1. Following transfection of PAR1-specific single siRNA, Western blotting confirmed suppression of PAR1 expression without alteration in vimentin expression (fig. 4a). PAR1 expression was also reduced after cells were transfected with a mixture of PAR 1 siRNAs (SMARTpool). No inhibitory effect on PAR2, PAR3 or PAR4 expression was observed. The siRNA SMARTpool negative control had no effect on PARs expression (fig. 4b). Transfection did not affect cell viability (data not shown). Cells with or without PAR1 siRNA transfection were then
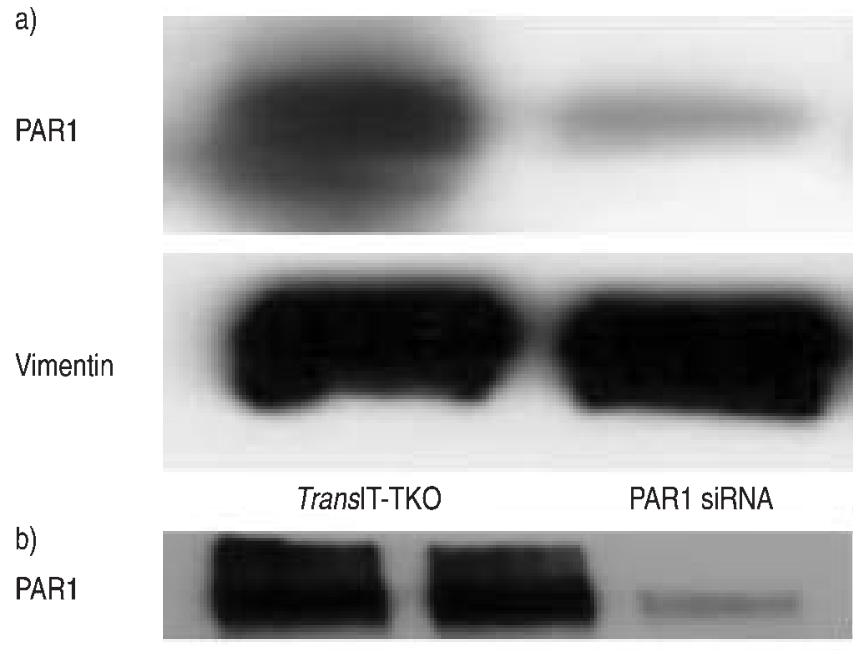

PAR2

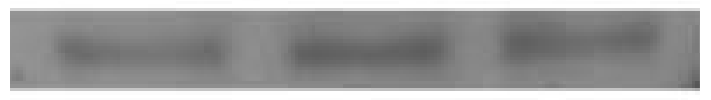

PAR3

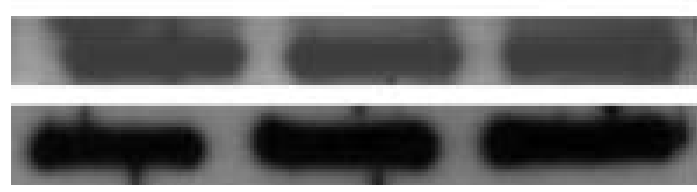

TransIT-TKO N siRNA PAR1 siRNA

Fig. 4. - Effect of protease-activated receptor (PAR) short interfering RNA (siRNA) on PAR expression in human foetal lung fibroblasts. a) Effect of single PAR1 siRNA transfection on PAR1 and vimentin expression. b) Effect of PAR1 siRNA SMARTpool (PAR siRNA) and siRNA SMARTpool negative control (N siRNA) transfection on PAR1, PAR2, PAR3 and PAR4 expression compared to control (TransIT-TKO).

cast into three-dimensional collagen gels and the ability of thrombin to augment collagen gel contraction was assessed. Transfection reagent alone had no effect on fibroblastmediated collagen gel contraction. In contrast, transfection with either PAR1 single siRNA (fig. 5a) or PAR1 siRNA SMARTpool (fig. 5b) significantly inhibited the augmented contraction induced by both thrombin and by the PAR 1 agonist. In contrast, siRNA to PAR1 had no effect on TGF$\beta 1$-induced contraction.

\section{Effects of PKC and calcium inhibitors on thrombin-induced collagen gel contraction}

To examine the potential role of the PKC pathway on thrombin-induced collagen gel contraction, collagen gels were stimulated with thrombin in the presence or absence of PKC inhibitors. A nonspecific PKC inhibitor, calphostin C, partially blocked the stimulatory effect of thrombin on collagen gel contraction. No inhibitory effect was observed with the conventional PKC isozyme inhibitor Gö6976 (fig. 6). In contrast, the PKC- $\varepsilon$ inhibitor Ro-31-8220 partially but significantly decreased collagen gel contraction augmented by thrombin. As novel PKC isozymes are independent of calcium, the effects of three kinds of calcium inhibitors on thrombin-induced collagen gel contraction were also measured. An intracellular calcium chelator (BAPTA/AM), EGTA and an inhibitor of intracellular calcium mobilisation (TMB8) had no effect on collagen gel contraction augmented by thrombin (data not shown).

The role of PKC- $\varepsilon$ was further evaluated by determining both the ability of thrombin and TFLLR to stimulate PKC- $\varepsilon$ 

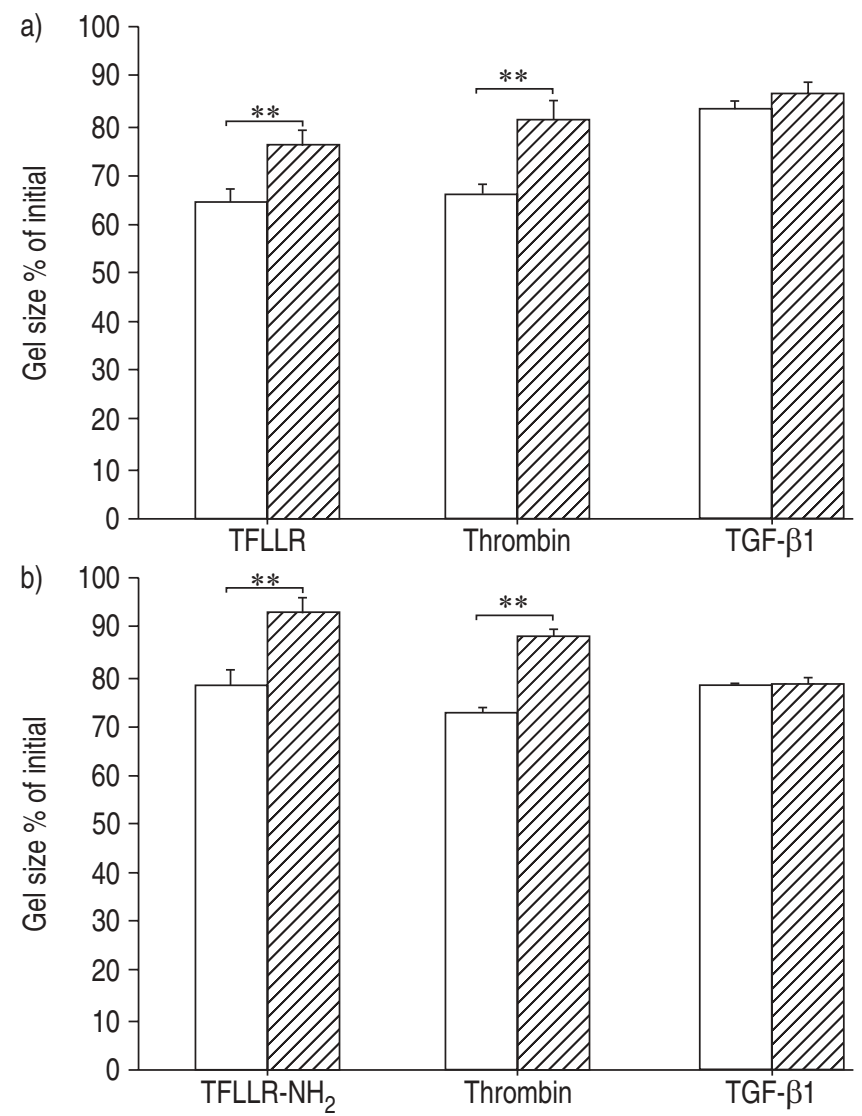

Fig. 5. - a) Effect of protease-activated receptor (PAR)1 knockdown mediated by a single PAR1 short interfering RNA (siRNA; $\mathbb{Z}$ ) on PAR1 agonist (TFLLR)-, thrombin- and transforming growth factor (TGF)- $\beta 1$-induced collagen gel contraction ( $\square$ ) in human foetal lung fibroblasts. b) Effect of PAR1 knockdown mediated by PAR1 siRNA SMARTpool (ש) on TFLLR-NH $2^{-}$, thrombin- and TGF- $\beta 1$-induced collagen gel contraction $(\square)$ in human foetal lung fibroblasts. **: $\mathrm{p}<0.01$. Data are presented as mean \pm SEM for three separate experiments, each of which included triplicate gels for each condition.

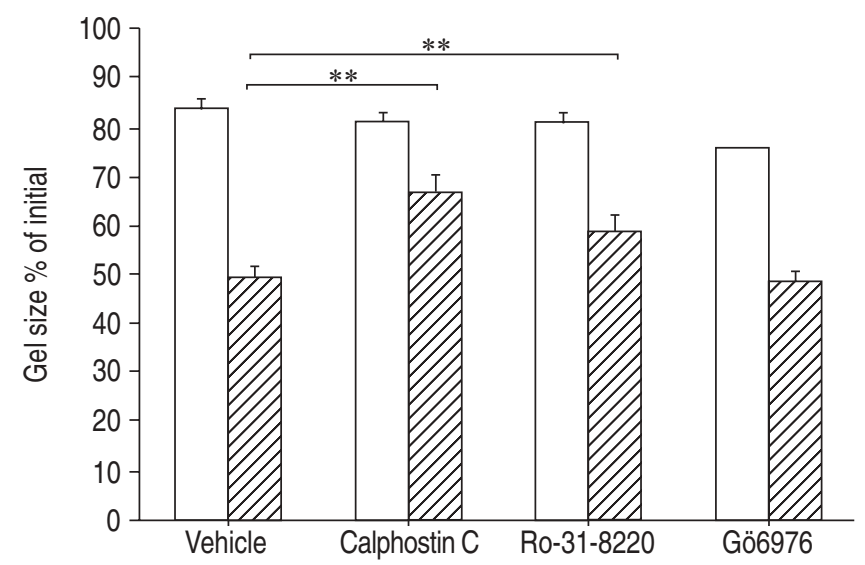

Fig. 6. - Effect of protein kinase C inhibitors ( $\square$ ) on thrombininduced collagen gel contraction $(\mathbb{Z})$. Data are presented as mean \pm SEM for three separate experiments, each of which included triplicate gels for each condition. **: $\mathrm{p}<0.01$.

activity and to determine whether it could be blocked by siRNA targeting PAR1 (fig. 7). Both thrombin and TFLLR significantly stimulated PKC- $\varepsilon$ activity measured directly in

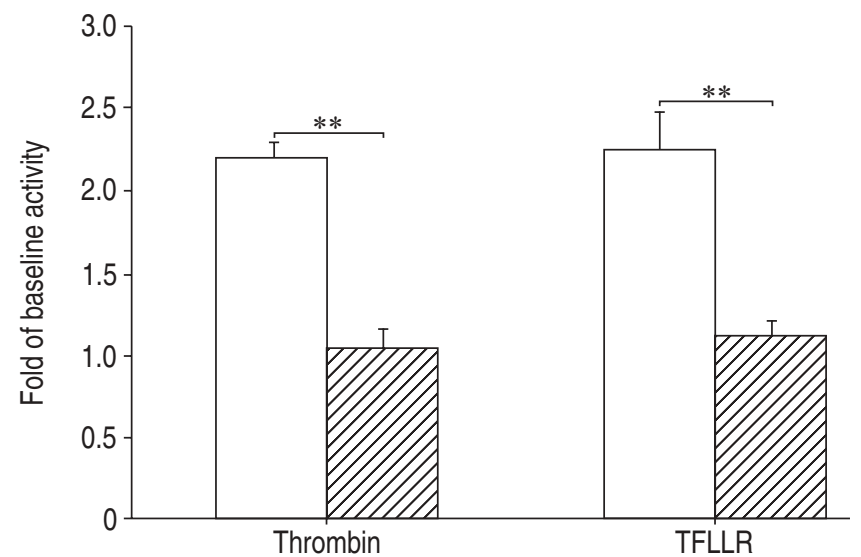

Fig. 7. - Effect of protease-activated receptor (PAR)1 knockdown (Z) on protein kinase $C-\varepsilon$ activity stimulated with thrombin and PAR1 agonist (TFLLR) ( $\square$ ) in human foetal lung fibroblasts. Data are presented as mean \pm SEM for three separate experiments, each of which included triplicate gels for each condition. ${ }^{* *}: p<0.01$.

HFL-1. In the presence of siRNA targeting PAR1, however, neither thrombin nor the PAR1 agonist stimulated PKC-E activity.

\section{Discussion}

The current study demonstrates that PAR 1 partially mediates thrombin-augmented contraction of three-dimensional collagen gels. Both thrombin and the PAR 1 agonist augmented contraction, and this was partially inhibited when PAR1 expression was suppressed by RNAi. Augmented gel contraction appears to depend on PKC- $\varepsilon$ activity, as both thrombin and TFLLR led to augmented PKC- $\varepsilon$ activation, and this was also blocked by RNAi. Inhibition of PKC- $\varepsilon$, moreover, was able to partially inhibit thrombin-augmented contraction, indicating that PKC- $\varepsilon$ is a downstream mediator in the pathway. Finally, the ability of thrombin to augment collagen gel contraction requires the proteolytic activity of the thrombin.

Activation of the blood coagulation system and generation of thrombin is common in the processes of tissue injury, inflammation and repair. In addition to its important role in haemostasis and thrombosis, thrombin mediates multiple other cellular functions. These include stimulating proliferation of various cell types [23-25]. In addition, thrombin can affect extracellular matrix deposition and degradation by promoting pro-collagen production from smooth muscle cells and fibroblasts, and activation of matrix metalloproteinase-2 produced by vascular smooth muscle cells [26, 27]. Thrombin may participate in tissue remodelling by several additional methods. Thrombin has been reported to stimulate fibroblastmediated contraction of three-dimensional matrices [28], an in vitro model of the tissue contraction which characterises fibrosis [4]. The current study supports a role for thrombin as a mediator of tissue remodelling through stimulating collagen gel contraction.

The PARs belong to the family of G-protein-coupled receptors. They are activated by a unique process: serine proteases cleave the extracellular $\mathrm{NH}_{2}$-terminal extension. This generates a new $\mathrm{NH}_{2}$ terminus, which serves as a tethered ligand that can interact intramolecularly and bind to the cleaved receptor inducing activation. Four members of the PAR family (PAR1, PAR2, PAR3 and PAR4) are known to date. PAR1, PAR3 and PAR4 are activated by thrombin. 
However, while the full spectrum of PAR-induced cellular activities remains to be defined, studies in a number of systems have suggested that PAR 1 plays a crucial role in mediating many effects induced by thrombin [16, 17, 29].

Several methods have been used to explore the role of specific PAR receptors. Peptides corresponding to the tethered ligands have been developed. In this context, TFLLR is considered to be the most selective and essential peptide to activate PAR $1[30,31]$ and has been used in many studies to help define the role of PAR1 [31-33]. This peptide, however, interacts with relatively low-binding affinity and, therefore, requires relatively high concentrations. Presumably the in vivo tethered ligand, by virtue of being retained near the receptor, can be effective even with the relatively low binding affinity. In the current study, TFLLR and TFLLR-NH $\mathrm{N}_{2}$ were used. Both had a stimulatory effect on collagen gel contraction and more potency was observed with TFLLR-NH 2 .

An alternate method to evaluate the receptor is the use of PAR1-gene-deficient (knockout) mice [25, 34]. The current study, which used human cells, used a similar method of suppressing PAR1 by exploiting the technique of RNAi [35, 36]. With this method, PAR 1 expression could be significantly inhibited and this was associated with inhibition of the effect of both thrombin and the selective PAR 1 agonist TFLLR/ TFLLR-NH $\mathrm{N}_{2}$. However, neither single PAR1 siRNA nor PAR1 siRNA SMARTpool were completely effective in blocking the effects of either thrombin or PAR 1 agonist. This could be due to incomplete suppression of PAR1 expression, which is usually observed with the method of RNAi. Alternatively, an effect of either thrombin or PAR1 agonist on receptors other than PAR1, including other PARs, cannot be excluded. The current study, however, clearly demonstrates that PAR1, at least in part, is responsible for the effect of thrombin.

Like most mediators, thrombin can act through a number of signal transduction pathways. Included among these are the PKCs [13, 16, 37]. PKC- $\varepsilon$, in particular, a member of the novel PKC sub-family, is a calcium-independent serine/ threonine kinase, expressed in lung fibroblasts, human airway smooth muscle cells, and many other cell types and tissues $[10,38,39]$. PKC- $\varepsilon$ has been shown to participate in the regulation of cytoskeletal reorganisation relating to cell adhesion and motility. PKC- $\varepsilon$ is required for cell spreading mediated by integrin $\beta 1$ and appears to be responsible for the regulation of HeLa cell adhesion to extracellular matrix [40, 41]. Prostaglandin $\mathrm{D}_{2}$-induced collagen gel contraction has been shown to be mediated through PKC- $\varepsilon$ activation [7]. The current study supports this role for PKC- $\varepsilon$ and demonstrates that activation of PKC- $\varepsilon$ by thrombin occurs through the PAR1 receptor. It also suggests that thrombin acts through what may be a common pathway to promote collagen gel contraction, i.e. PKC-E. Data in the present study, moreover, indicates that thrombin-induced gel contraction is independent of calcium mobilisation, consistent with its action through a novel PKC isozyme.

The present study demonstrates that thrombin-augmented contraction of collagen gels is mediated, at least in part, through PAR1. However, it is possible that other signalling pathways could also contribute. In this regard, the siRNA experiments only partially blocked the thrombin effect. It is not possible to determine if this is due to incomplete suppression of PAR 1 expression or to alternate pathways contributing to the thrombin effect. Moreover the current study was performed with the HFL-1 cell strain [42]. This strain of normal human lung fibroblasts has been used extensively to assess fibroblast biology. Fibroblasts, however, are heterogeneous, and to what extent various signalling pathways contribute in other types of fibroblasts remains to be determined. The possibility that other pathways also contribute raises the interesting possibility that inhibition of additional mechanisms could synergise with inhibitors of the PAR1 pathway.

Remodelling of structural tissues with the accumulation of fibrosis is a characteristic feature of many interstitial lung diseases. Similar processes also occur in airways diseases such as asthma and COPD [1-3]. It has been suggested that this airway remodelling is a major cause of airway narrowing and fixed airflow limitation. In this context, increased levels of thrombin have been observed in lung diseases, including asthma and scleroderma $[14,15]$. The current study supports the concept that thrombin could contribute to the pathogenesis of fibrotic alterations in a variety of lung diseases. However, in addition to thrombin, other proteases can also cleave PARs [43, 44]. The role these proteases may play in PAR-modulated tissue remodelling remains to be defined. However, the fact that various proteases and protease inhibitors could interact through such signalling mechanisms raises interesting possibilities for coordinated control of remodelling processes.

In conclusion, thrombin is capable of stimulating collagen gel contraction mediated by fibroblasts. This action may contribute to the regulation of tissue repair and remodelling responses consequent to the thrombin activation that occurs following inflammation and injury. This effect of thrombin is mediated by the protease-activated receptor 1 and acts through protein kinase $\mathrm{C}-\varepsilon$. Defining this action of thrombin and its signalling pathways may help define the mechanisms that underlie tissue remodelling in diseases such as asthma and chronic obstructive pulmonary disease, and may help define new therapies for these disorders.

Acknowledgements. The authors acknowledge the excellent secretarial support of L. Richards.

\section{References}

1. Weibel ER, Crystal RG. Structural organization of the pulmonary interstitium. In: Crystal RG, West JB, eds. The Lung: Scientific Foundations. Philadelphia, Lippincott-Raven, 1997: pp. 685-695.

2. Brewster CE, Howarth PH, Djukanovic R, Wilson J, Holgate ST, Roche WR. Myofibroblasts and subepithelial fibrosis in bronchial asthma. Am J Respir Cell Mol Biol 1990; 3: $507-511$.

3. Nagai A. Pathology and pathophysiology of chronic obstructive pulmonary disease. Intern Med 2002; 41: 265269.

4. Bell E, Ivarsson B, Merrill C. Production of a tissue-like structure by contraction of collagen lattices by human fibroblasts of different proliferative potential in vitro. Proc Natl Acad Sci USA 1979; 76: 1274-1278.

5. Zent R, Ailenberg M, Silverman M. Tyrosine kinase cell signaling pathways of rat mesangial cells in 3-dimensional cultures: Response to foetal bovine serum and plateletderived growth factor-BB. Exp Cell Res 1998; 240: 134-143.

6. Liu XD, Umino T, Ertl R, et al. Persistence of TGF- $\beta 1$ induction of increased fibroblast contractility. In Vitro Cell Dev Biol Anim 2001; 37: 193-201.

7. Kohyama $\mathrm{T}$, Wyatt $\mathrm{TA}$, Liu $\mathrm{X}$, et al. $\mathrm{PGD}_{2}$ modulates fibroblast-mediated native collagen gel contraction. $\mathrm{Am} \mathrm{J}$ Respir Cell Mol Biol 2002; 27: 375-381.

8. Mio T, Liu X, Toews ML, Rennard SI. Lysophosphatidic acid augments fibroblast-mediated contraction of released collagen gels. J Lab Clin Med 2002; 139: 20-27.

9. Mio T, Liu X, Toews ML, et al. Bradykinin augments fibroblast-mediated contraction of released collagen gels. Am J Phys 2001; 281: L164-L171. 
10. Akita Y. Protein kinase C- $\varepsilon$ (PKC- $\varepsilon$ ): its unique structure and function. $J$ Biochem (Tokyo) 2002; 132: 847-852.

11. Zhu YK, Liu X-D, Skold CM, et al. Cytokine inhibition of fibroblast-induced gel contraction is mediated by PGE2 and NO Acting through separate parallel pathways. Am J Resp Cell Mol Biol 2001; 25: 245-253.

12. Skold CM, Liu X, Zhu YK, et al. Glucocorticoids augment fibroblast mediated contraction of collagen gels by inhibition of endogenous PGE production. Proc Assn Am Phys 1999; 111: 249-258.

13. Strukova SM. Thrombin as a regulator of inflammation and reparative processes in tissues. Biochemistry (Mosc) 2001; 66: 8-18.

14. Ohba T, McDonald JK, Silver RM, Strange C, LeRoy EC, Ludwicka A. Scleroderma bronchoalveolar lavage fluid contains thrombin, a mediator of human lung fibroblast proliferation via induction of platelet-derived growth factor a-receptor. Am J Respir Cell Mol Biol 1994; 10: 405-412.

15. Gabazza EC, Taguchi O, Tamaki S, et al. Thrombin in the airways of asthmatic patients. Lung 1999; 177: 253-262.

16. Dery O, Corvera CU, Steinhoff M, Bunnett NW. Proteinaseactivated receptors: novel mechanisms of signaling by serine proteases. Am J Physiol 1998; 274: C1429-C1452.

17. Macfarlane SR, Seatter MJ, Kanke T, Hunter GD, Plevin R. Proteinase-activated receptors. Pharmacol Rev 2001; 53: 245282.

18. Elsdale T, Bard J. Collagen substrata for studies on cell behaviour. J Cell Biol 1972; 54: 626-637.

19. Mio T, Adachi Y, Romberger DJ, Ertl RF, Rennard SI. Regulation of fibroblast proliferation in three dimensional collagen gel matrix. In Vitro Cell Dev Biol 1996; 32: 427-433.

20. Elbashir SM, Harborth J, Weber K, Tuschl T. Analysis of gene function in somatic mammalian cells using small interfering RNAs. Methods 2002; 26: 199-213.

21. Hannun YA, Loomis CR, Bell RM. Activation of protein kinase $\mathrm{C}$ by Triton $\mathrm{X}-100$ mixed micelles containing diacylglycerol and phosphatidylserine. J Biol Chem 1985; 260: 10039-10043.

22. Roskoski R Jr. Assays of protein kinase. Methods Enzymol 1983; 99: 3-6.

23. Panettieri RA Jr, Hall IP, Maki CS, Murray RK. $\alpha$ Thrombin increases cytosolic calcium and induces human airway smooth muscle cell proliferation. Am J Respir Cell Mol Biol 1995; 13: 205-216.

24. Lin CC, Shyr MH, Chien CS, et al. Mechanisms of thrombin-induced MAPK activation associated with cell proliferation in human cultured tracheal smooth muscle cells. Cell Signal 2001; 13: 257-267.

25. Trejo J, Connolly AJ, Coughlin SR. The cloned thrombin receptor is necessary and sufficient for activation of mitogenactivated protein kinase and mitogenesis in mouse lung fibroblasts. Loss of responses in fibroblasts from receptor knockout mice. J Biol Chem 1996; 271: 21536-21541.

26. Chambers RC, Dabbagh K, McAnulty RJ, Gray AJ, BlancBrude OP, Laurent GJ. Thrombin stimulates fibroblast procollagen production via proteolytic activation of protease-activated receptor 1. Biochem J 1998; 333: 121-127.

27. Galis ZS, Kranzhofer R, Fenton JW 2nd, Libby P. Thrombin promotes activation of matrix metalloproteinase2 produced by cultured vascular smooth muscle cells. Arterioscler Thromb Vasc Biol 1997; 17: 483-489.

28. Bogatkevich GS, Tourkina E, Silver RM, Ludwicka-Bradley
A. Thrombin differentiates normal lung fibroblasts to a myofibroblast phenotype via the proteolytically activated receptor-1 and a protein kinase C-dependent pathway. $J$ Biol Chem 2001; 276: 45184-45192.

29. Coughlin SR. How the protease thrombin talks to cells. Proc Natl Acad Sci USA 1999; 96: 11023-11027.

30. Hollenberg MD. Proteinase-mediated signaling: proteinaseactivated receptors (PARs) and much more. Life Sci 2003; 74: $237-246$.

31. Hollenberg MD, Saifeddine M, al-Ani B, Kawabata A. Proteinase-activated receptors: structural requirements for activity, receptor cross-reactivity, and receptor selectivity of receptor-activating peptides. Can J Physiol Pharmacol 1997; 75: 832-841.

32. Chambers RC, Leoni P, Blanc-Brude OP, Wembridge DE, Laurent GJ. Thrombin is a potent inducer of connective tissue growth factor production via proteolytic activation of protease-activated receptor-1. J Biol Chem 2000; 275: 35584 35591.

33. Scarborough RM, Naughton MA, Teng W, et al. Tethered ligand agonist peptides. Structural requirements for thrombin receptor activation reveal mechanism of proteolytic unmasking of agonist function. J Biol Chem 1992; 267: 13146-13149.

34. Rondeau E, Vigneau C, Berrou J. Role of thrombin receptors in the kidney: lessons from PAR1 knock-out mice. Nephrol Dial Transplant 2001; 16: 1529-1531.

35. Hannon GJ. RNA interference. Nature 2002; 418: 244-251.

36. McManus MT, Haines BB, Dillon CP, et al. Small interfering RNA-mediated gene silencing in T lymphocytes. J Immunol 2002; 169: 5754-5760.

37. Grand RJ, Turnell AS, Grabham PW. Cellular consequences of thrombin-receptor activation. Biochem J 1996; 313: 353368.

38. Pang L, Nie M, Corbett L, Donnelly R, Gray S, Knox AJ. Protein kinase $\mathrm{C}-\varepsilon$ mediates bradykinin-induced cyclooxygenase-2 expression in human airway smooth muscle cells. Faseb J 2002; 16: 1435-1437.

39. Tourkina E, Hoffman S, Fenton JW 2nd, Lipsitz S, Silver RM, Ludwicka-Bradley A. Depletion of protein kinase $\mathrm{C} \varepsilon$ in normal and scleroderma lung fibroblasts has opposite effects on tenascin expression. Arthritis Rheum 2001; 44: $1370-1381$.

40. Berrier AL, Mastrangelo AM, Downward J, Ginsberg M, LaFlamme SE. Activated R-ras, Rac1, PI 3-kinase and PKC $\varepsilon$ can each restore cell spreading inhibited by isolated integrin $\beta 1$ cytoplasmic domains. J Cell Biol 2000; 151: 1549-1560.

41. Chun JS, Ha MJ, Jacobson BS. Differential translocation of protein kinase $\mathrm{C} \varepsilon$ during HeLa cell adhesion to a gelatin substratum. J Biol Chem 1996; 271: 13008-13012.

42. Breul SD, Bradley KH, Hance AJ, Schafer MP, Berg RA, Crystal RG. Control of collagen production by human diploid lung fibroblasts. J Biol Chem 1980; 255: 5250-5260.

43. Berger P, Tunon-De-Lara JM, Savineau JP, Marthan R. Selected contribution: tryptase-induced PAR-2-mediated $\mathrm{Ca}(2+)$ signaling in human airway smooth muscle cells. J Appl Physiol 2001; 91: 995-1003.

44. Miyata S, Koshikawa N, Yasumitsu H, Miyazaki K. Trypsin stimulates integrin $\alpha(5) \beta(1)$-dependent adhesion to fibronectin and proliferation of human gastric carcinoma cells through activation of proteinase-activated receptor-2. $J$ Biol Chem 2000; 275: 4592-4598. 